\title{
Is it Visible? Micro-artefacts' Nonlinear Structure and Natural Formation Processes
}

\author{
Dimitris Kontogiorgos ${ }^{1}$ and Alexandros Leontitsis 2,3 \\ 1Weiner Laboratory, American School of Classical Studies at Athens, Athens, \\ ${ }^{2}$ Department of Education, University of Ioannina, 45110 - Dourouti, Ioannina, \\ ${ }^{3}$ Center for Research and Applications of Nonlinear Systems, University of Patras, \\ 26500 - Rio, Patras, \\ Greece
}

\section{Introduction}

Micro-artefacts (i.e., cultural particles smaller than $2 \mathrm{~mm}$ in diameter), due to their abundance and incorporation in an archaeological deposit constitute a significant part of the cultural particles present, and their analysis can assist the archaeological interpretation (Stein, 1987). The analysis of micro-artefacts is extensively complex due to the different micro-artefact categories that may appear in an archaeological context and also because of the number of different cultural (and natural) formation processes that may have been involved in the creation of characteristics specific to an archaeological context.

Recently, a non-linear data analysis technique (S-SOFM) was applied on micro-artefact data. The technique revealed hidden structures among the data that linear methods were unable to classify and also offered an additional way to unfold cultural information encoded within them (i.e., micro-artefacts), and thereby, observe the dynamics of cultural factors in site formation processes (Kontogiorgos et al., 2007). The spherical self-organizing feature map method was implemented in this study to perform the initial pattern searching operation in a sample of 4-dimensional micro-artefact data shaped only by the effects of natural formation processes (hereafter: N.F.P.), and so further explore the developed visualization tool as a means to identify patterns in micro-artefacts prior to their detailed analysis. An example is given on micro-artefact data from the colluvial deposit, covering the theatre of the Hellenistic period, located outside the city walls of the Hellenistic city of Gitana in the Thesprotia region-Epirus-NW Greece (Kontogiorgos and Preka, 2009). Section 2 briefly describes how the spherical self-organizing map creates a 3D visual or graphical representation of the data. Section 3 applies the method on a sample of 4-dimensional microartefact data. General findings and concluding remarks are presented in Section 4.

\section{Spherical self-organizing feature map}

The Self-Organizing Feature Map (SOFM), introduced by Kohonen (1981), maps ndimensional data into a low-dimensional space. The spherical SOFM (Sangole, 2003) the 
low-dimensional space is a tessellated sphere that is formed by subdividing an icosahedron. Every vertex on this sphere is a strategic location of an n-dimensional vector that represents an ensemble of similar data vectors which are assigned to the vector during the mapping operation. It is therefore necessary to visually enhance variations in the data using the physical attributes of the mapping lattice. The benefit of a spherical lattice in the implementation of the SOFM is that the enclosed space can be used to generate a 3D visual representation of some physical aspect of the n-dimensional data.

Conventional implementation of the SOFM method have used a $2 \mathrm{D}$ lattice as the lowdimensional space, and associations in the data are visualized by means of a terrain map, wherein elevation represents some aspect of the vector(s) at that location (Vesanto, 1999; Ultsch and Siemon, 1990). Relative similarity between data vectors mapped into the sphere can be visualized by introducing distortions in the sphere accompanied by changes in the colour. Informative characteristics of the data are reflected as distortions and colour gradations on the surface of the sphere. The formulation of these measures is a non-trivial task and often application dependent. The measures reflect desired data correlations (either linear or non-linear) and must be defined by the researcher who is familiar with the underlying data set. It is this aspect of the S-SOFM that differs from existing literature about the self-organizing feature map. The S-SOFM utilizes the spherical lattice of the SOFM space to generate a visual form of the clustered data that is more intuitive and easy to perceive. A visual form of the data is created by scaling the radial distance of the vertices on the sphere in proportion to a measure characterizing some physical aspect of the data. Examples illustrating the various implementations of the spherical SOFM on different data and the use of possible measures to create spherical SOFM graphical representations are discussed in Sangole (2003) and Sangole and Knopf (2003).

\section{Implementation of the S-SOFM on micro-artefact data}

\subsection{Previous work on micro-artefacts from the site}

The systematic excavation in the theatre of the Hellenistic period (ca. 330 B.C-167 B.C) at Gitana (Thesprotia region-Epirus-NW Greece) during five seasons (1996-1997 and 20052008) has brought into light the auditorium of the theatre below a thick (ca. $1.25 \mathrm{~m}-1.50 \mathrm{~m}$ ) colluvial deposit. The source of the colluvial deposit was thought to be sediments and cultural materials eroded from the abandoned Hellenistic city of Gitana, once expanded on top of the theatre (Kontogiorgos and Preka, 2009). Although is impossible to assess whether micro-artefacts ended up in the deposit as micro-materials or were generated after deposition; however, since the identified micro-artefact types (i.e., shell, bone, burnt clay) come from fragile or size unstable materials, their density trends (i.e., peaks and irregularity) might have been produced post-depositionally from the effects of the different N.F.P. (i.e., erosion, in situ weathering and translocation of smaller cultural sedimentary particles) that affected the larger macro-artefacts (Sherwood et al., 1995) present in the deposit.

In this case, since anthropogenic activity was absent from the site after abandonment, their variability most likely depicts the intensity of these types of formation processes (i.e., N.F.P.) and possibly the time span capable of producing variable micro-artefact concentrations (Kontogiorgos and Preka, 2009). 


\subsection{Laboratory procedures}

A total of forty four (44) sediment samples weighing ca $1000 \mathrm{~g}$ each, were collected from five (5) columns, mostly at $10 \mathrm{~cm}$ vertical intervals, providing good coverage across the exposed stratigraphy of the deposit, and were labeled according to depth. The laboratory procedure used two divisions of the phi (ф) scale: - 2.00ф and 0ф. Contents of the bulk samples were passed through a stack of $4 \mathrm{~mm}(-2.00 \phi)$ and $1 \mathrm{~mm}(0 \phi)$ sieves. The material retained in the $1 \mathrm{~mm}$ sieve created the sub-sample that was processed for microartifacts and an optical microscope was used for identifications. To avoid damaging the artefactual contents (e.g., shell, bone) there was no pretreatment for removal of organic matter or carbonate. The subsample was saturated with $1 \%$ sodium hexametaphoshate and washed through the $1 \mathrm{~mm}$ sieve to separate the sand fraction from the silt/clay fraction. For each sub-sample, 500 particles were point-counted.

The identified micro-artefact types were: Microfragments of Burnt Clay, Microbone, Microshell. To deal efficiently with the large numbers of samples derived from the contexts, and reduce the processing time, the point-counting procedure had to be applied. The procedure for determining the proportions of compositional types follows the one described by Stein and Telster (1989). A small fraction of the sub-sample was poured gradually, into a glass petri-dish, below which was attached a piece of graph paper of no greater than $1 \mathrm{~cm}$ graph intervals. The particles are spread evenly across the grid. While looking through the optical microscope, the particles located in one grid unit were counted according to compositional types.

To improve the identifications and to observe more accurately the measurement error, 100 particles were counted and recorded each time, until a total of 500 particles were examined, since in the previous exercise a good stabilisation of the point estimation between 250 and 500 counted particles was achieved (Kontogiorgos and Leontitsis, 2005;2009).

\subsection{Seeing the unseen! N.F.P. creating micro-artefact patterning}

The construction of the S-SOFM graphical representation was based on a database of 44 three-dimensional records, each dimension representing a micro-artefact category. Every row represented the point-counting results (Kontogiorgos and Leontitsis, 2009). A sphericalSOFM graphical representation was created as described in Sangole (2003), Sangole and Knopf (2003) and Leontitsis and Sangole (2005). The glyph was generated after 20 epochs (training cycles). Three views of the resulting S-SOFM graphical representation are illustrated in Fig. 1 showing the formation of a distinct black region. A nonlinear microartefact structure lies within this statistical space which can be distinguished into a separate sub-structure. The spherical-SOFM pattern recognition procedure therefore serves as the initial step in the analysis of the multidimensional micro-artefact data. It provides a comprehensive preliminary visual representation of inherent non-linear characteristics in data. In this example one meaningful component was revealed, which appeared to be the determinant for the constitution of the analyzed data set.

The results of this study suggest that the proposed implementation of the spherical-SOFM non-linear method is able to recognize and to provide a visual representation of microartefact patterns prior to performing any further analysis on the data. It also depicts the ability of the N.F.P. to create patterns in micro-artefacts. The implication is that these complex multidimensional data (i.e., micro-artefacts) should be used with care due to the many factors that may account for the observed pattern and should not be simply used to 
reflect 'noise' in larger artefacts (e.g., Dunnell and Stein, 1989). Finally, this exercise enhances attempts for developing interpretations on micro-artefact patterning by providing strong pattern recognition.

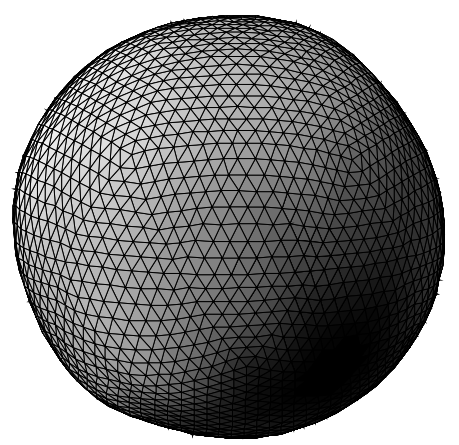

(a)

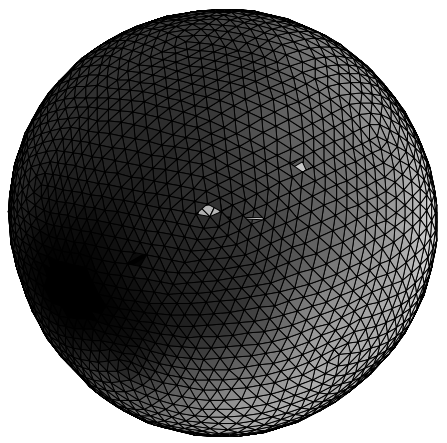

(b)

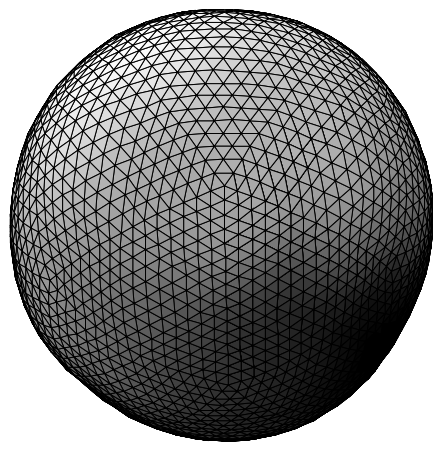

(c)

Fig. 1(a-c). Three views of the S-SOFM graphical representation showing the formation of distinct black region corresponding to the micro-artefact data 
The next step will be to understand the reasons for this pattern by further investigating either the proportional relationships between micro-artefact types (Kontogiorgos, 2008) and/or by a complete geoarchaeological analysis of archaeological sediments which has shown concentration (i.e., peaks) of micro-artefacts in fine sediment attributable possibly to the effects of N.F.P. to produce such concentration of micro-artefacts in an archaeological deposit lacking any anthropogenic activity (Kontogiorgos and Preka, 2009).

\section{Conclusions}

A non-linear data analysis technique, the spherical self-organizing feature map, was applied on micro-artefact data. This technique revealed patterns among the data created by N.F.P further suggesting care when interpreting micro-artefacts. The implementation of the method needs to be explored in other site contexts and further tested. Given the abundance of large data sets of micro-artefacts, it will be a useful visualisation tool for the researcher to facilitate a quick search and identification of possible micro-artefact patterns in soil samples prior to performing any detailed analysis of the complex multidimensional data.

\section{References}

Dunnell, R.C. \& Stein, J.K. (1989). Theoretical issues in the interpretation of microartifacts. Geoarchaeology 4 (1), pp. 31-42.

Kontogiorgos, D. \& Leontitsis, A. (2005). Micro-artefacts weight estimation by Genetic Algorithm minimisation. Journal of Archaeological Science 32, 1275-1282.

Kontogiorgos, D., Leontitsis, A. \& Sangole, A. (2007). Telling a non-linear story: the exploration of micro-artefacts' non-linear structure. Journal of Archaeological Science 34, pp. 1532-1536.

Kontogiorgos, D. (2008). Geoarchaeological and Microartifact Analysis of Archaeological Sediments. A Case study From a Neolithic Tell Site in Greece. Nova Science Publishers, Inc., New York.

Kontogiorgos, D. \& Leontitsis, A. (2009). Test again for the optimum! Confirming the Use of Genetic Algorithm Minimization on Microartifact Weight Estimation. In: On Site Geoarchaeology on a Neolithic Tell Site in Greece: Archaeological Sediments, Microartifacts and Softwear Development, Kontogiorgos, D. (Ed)., Nova Science Publishers, Inc., New York.

Kontogiorgos, D. \& Preka, K. (2009). From Neolithic to Hellenistic. A Geoarchaeological Approach to the Burial of the a Hellenistic Theatre: The Evidence from Particle Size Analysis and Microartifacts. In: On Site Geoarchaeology on a Neolithic Tell Site in Greece: Archaeological Sediments,Microartifacts and Softwear Development, Kontogiorgos, D. (Ed)., Nova Science Publishers, Inc., New York.

Kohonen, T. (1981). Self-organized formation of topologically correct feature maps. Biological Cybernetics 43, pp. 59-69.

Leontitsis, A.\& Sangole, A.P. (2005). Estimating an optimal neighborhood size in the spherical self-organizing feature map. International Journal of Computational Intelligence 2, pp. 94-98.

Sangole A. (2003) Data-driven modeling using spherical self-organizing feature maps, PhD thesis, University of Western Ontario, Canada; Universal Publishers (ISBN 1-58112319-1). 
Sangole, A. \& Knopf, G.K. (2003). Visualization of random ordered numeric data sets using self-organized feature maps. Computers and Graphics 27, 963-976.

Stein, J.K. (1987). Deposits for archaeology, Advances in Archaeological Method and Theory 11, pp. 337-392.

Stein, J.K. \& Telster, P.A. (1989). Size distributions of artefact classes: combining macro- and micro-fractions. Geoarchaeology 4 (1), pp. 1-30.

Sherwood, S.C. (2001). Microartifacts. In: Earth Sciences and Archaeology, P.Goldberg, V.T. Holiday, R. Ferring (Eds.), Academic/Plenum Pubs, pp. 327-351.

Sherwood, S.C., Simek, J.F. \& Polhemus, R.R. (1995). Artifact size and spatial process: macroand microartifacts in a Mississipian House. Geoarchaeology 10 (6), pp. 429-455.

Vesanto, J. (1999). SOM-based data visualization methods. Journal of Intelligent Data Analysis 3, pp. 111-126.

Ultsch, A., Siemon, H.P. (1990). Kohonen's self-organizing feature maps for exploratory data analysis. Proceedings of the International Neural Network Conference. Dordrecht, The Netherlands, pp. 305-308. 


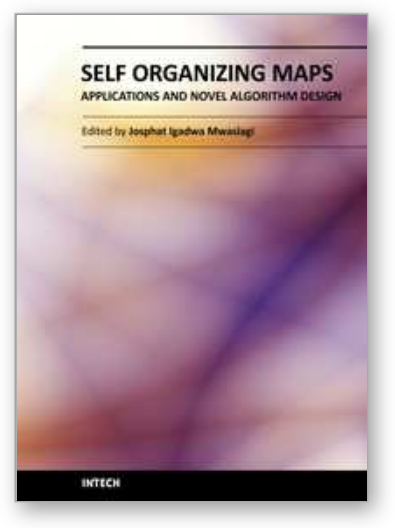

\author{
Self Organizing Maps - Applications and Novel Algorithm Design \\ Edited by Dr Josphat Igadwa Mwasiagi
}

ISBN 978-953-307-546-4

Hard cover, 702 pages

Publisher InTech

Published online 21, January, 2011

Published in print edition January, 2011

Kohonen Self Organizing Maps (SOM) has found application in practical all fields, especially those which tend to handle high dimensional data. SOM can be used for the clustering of genes in the medical field, the study of multi-media and web based contents and in the transportation industry, just to name a few. Apart from the aforementioned areas this book also covers the study of complex data found in meteorological and remotely sensed images acquired using satellite sensing. Data management and envelopment analysis has also been covered. The application of SOM in mechanical and manufacturing engineering forms another important area of this book. The final section of this book, addresses the design and application of novel variants of SOM algorithms.

\title{
How to reference
}

In order to correctly reference this scholarly work, feel free to copy and paste the following:

Dimitris Kontogiorgos and Alexandros Leontitsis (2011). Is It Visible? Micro-Artefacts' Non-Linear Structure and Natural Formation Processes, Self Organizing Maps - Applications and Novel Algorithm Design, Dr Josphat Igadwa Mwasiagi (Ed.), ISBN: 978-953-307-546-4, InTech, Available from:

http://www.intechopen.com/books/self-organizing-maps-applications-and-novel-algorithm-design/is-it-visiblemicro-artefacts-non-linear-structure-and-natural-formation-processes

\section{INTECH}

open science | open minds

\author{
InTech Europe \\ University Campus STeP Ri \\ Slavka Krautzeka 83/A \\ 51000 Rijeka, Croatia \\ Phone: +385 (51) 770447 \\ Fax: +385 (51) 686166 \\ www.intechopen.com
}

\author{
InTech China \\ Unit 405, Office Block, Hotel Equatorial Shanghai \\ No.65, Yan An Road (West), Shanghai, 200040, China \\ 中国上海市延安西路65号上海国际贵都大饭店办公楼 405 单元 \\ Phone: +86-21-62489820 \\ Fax: +86-21-62489821
}


(C) 2011 The Author(s). Licensee IntechOpen. This chapter is distributed under the terms of the Creative Commons Attribution-NonCommercialShareAlike-3.0 License, which permits use, distribution and reproduction for non-commercial purposes, provided the original is properly cited and derivative works building on this content are distributed under the same license. 